\title{
Market Basket Analysis untuk Swalayan KSU Sumber Makmur dengan Algoritma FP Growth
}

\author{
Ramadhan, Teknologi Informasi Institut Sains dan Teknologi Terpadu Surabaya, \\ Esther Irawati Setiawan, Teknik Informatika Institut Sains dan Teknologi Terpadu Surabaya.
}

\begin{abstract}
Abstrak-Salah satu teknik data mining yang populer digunakan adalah association data mining atau yang biasa disebut dengan istilah market basket analysis. Market basket didefinisikan sebagai suatu itemset yang dibeli secara bersamaan oleh pelanggan dalam suatu transaksi. Market basket analysis adalah suatu sarana untuk meningkatkan penjualan. Metode ini dimulai dengan mencari sejumlah frequent itemset dan dilanjutkan dengan pembentukan aturanaturan asosiasi. Algoritma Apriori dan frequent pattern growth adalah dua algoritma yang sangat populer untuk menemukan sejumlah frequent itemset dari data-data transaksi yang tersimpan dalam basis data. Dalam penelitian ini algoritma frequent pattern growth (FP Growth) digunakan untuk menemukan sejumlah aturan asosiasi dari basis data transaksi penjualan di Swalayan KSU Sumber Makmur (Trenggalek). Dari hasil pengolahan data didapatkan pola pembelian paling kuat berupa jika membeli pasta gigi maka dimungkinkan juga akan membeli sabun dan jika membeli shampo juga akan membeli sabun dengan tingkat keyakinan (confidence) $63 \%$ dan $62 \%$.
\end{abstract}

Kata Kunci-data mining, association rules, market basket analysis, Apriori, FP-growth.

\section{Pendahuluan}

$\mathrm{S}$ istem komputerisasi dapat membantu pencatatan dan pengolahan data transaksi pembelian dan penjualan barang di toko swalayan atau supermarket. Penggunaan sistem komputerisasi tersebut umumnya terbatas untuk pengelolaan barang. Swalayan KSU Sumber Makmur Trenggalek telah menggunakan sistem komputerisasi untuk mencatat transaksi penjualan tetapi belum dimanfaatkan untuk mendapatkan knowledge untuk meningkatkan transaksi penjualan.

Market Basket Analysis merupakan sebuah analisis terhadap kebiasaan customer berbelanja pada supermarket dengan cara menemukan asosiasi dan korelasi di antara berbagai macam item yang dimasukkan customer di dalam keranjang belanjaannya. Market Basket Analysis paling banyak digunakan untuk menganalisa data dalam rangka keperluan strategi pemasaran, desain katalog, dan proses pembuatan keputusan bisnis.

Ramadhan, Departemen Teknologi Informasi, Institut Sains dan Teknologi Terpadu Surabaya, Surabaya, Jawa Timur, Indonesia (e-mail: radokdr@gmail.com)

Esther Irawati Setiawan, Departemen Teknologi Informasi, Institut Sains dan Teknologi Terpadu Surabaya, Surabaya, Jawa Timur, Indonesia (e-mail: esther@stts.edu)
Produk-produk yang sering dibeli secara bersamaan dapat ditempatkan secara berdekatan sehingga konsumen dapat dengan mudah menemukan apa yang dicari. Dengan demikian para konsumen akan merasa puas dan penjualan juga akan meningkat. Market Basket Analysis bertujuan untuk mengetahui item apa saja yang sering dibeli bersamaan oleh customer. Item di sini diartikan sebagai berbagai macam produk atau barang pada supermarket.

Banyak algoritma yang bisa digunakan untuk melakukan mining frequent itemset untuk mengetahui hubungan antar item dalam transaksi penjualan. Apriori adalah algoritma pertama dan menjadi dasar dalam pencarian frequent itemset yang diusulkan oleh R. Agrawal dan R. Srikant di tahun 1994 [1]. FP Growth merupakan algoritma yang saat ini dikenal cepat dan umum digunakan tanpa pembangkitan candidate generation. FP Growth meringkas informasi transaksi ke dalam bentuk pohon.

\section{TINJAUAN PUSTAKA}

\section{A. Market Basket Analisys}

Pada paper [3] disebutkan bahwa market basket analisys atau analisis keranjang belanja memiliki tujuan untuk mengidentifikasi produk, atau kelompok produk, yang cenderung terjadi bersamaan (terkait) dalam transaksi pembelian (keranjang). Pengetahuan yang diperoleh dari analisis keranjang belanja bisa sangat berharga; misalnya, dapat digunakan oleh supermarket untuk mengatur ulang tata letaknya, mengambil produk yang sering dijual bersama dan menempatkannya berdekatan. Dapat juga digunakan untuk meningkatkan efisiensi promosi: produk yang terkait seharusnya tidak dipromosikan pada saat yang sama. Dengan mempromosikan secara tepat salah satu produk terkait memungkinkan meningkatkan penjualan produk itu dan mendapatkan penjualan yang menyertainya peningkatan untuk produk terkait. Basis data Untuk analisis keranjang belanja terdiri dari semua transaksi yang dilakukan dalam periode penjualan tertentu (misalnya satu tahun) dan di lokasi penjualan tertentu (misalnya di suatu lokasi supermarket). Konsumen bisa tampil lebih dari sekali di database. Bahkan, konsumen akan muncul didatabase setiap kali mereka melakukan transaksi di lokasi penjualan. Tujuan dari analisis ini adalah untuk menemukan yang terbaik kombinasi produk yang sering dibeli oleh pelanggan.

Penulis melakukan penelitian pada implementasi metode data mining untuk Six Sigma metodologi. Kemudian dipilih 
market basket analysis untuk meningkatkan fase, dengan itu untuk memprediksi kebiasaan pelanggan.

\section{B. Analisis Asosiasi}

Pada paper [2] penulis melakukan penelitian tentang seberapa efektif metode FP Growth. Ekperimen dilakukan dengan 2 jenis data yang memiliki 10 ribu dan 100 ribu transaksi. Eksperimen dilakukan menggunakan algoritma Apriori dan FP Growth. Perbandingan waktu proses ditunjukkan oleh Gambar. 1.

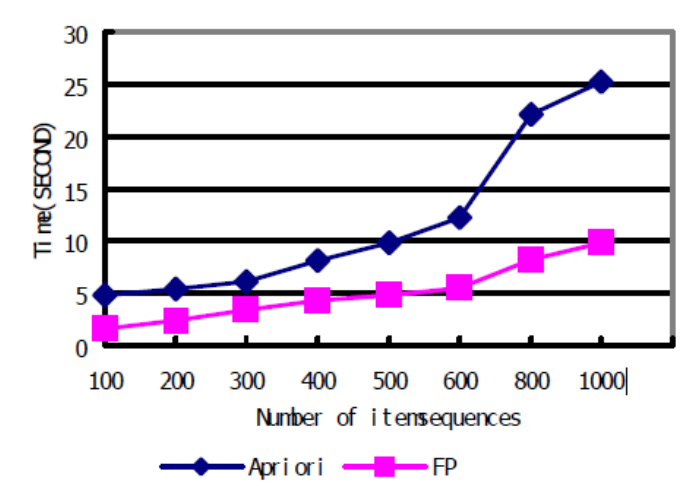

Gambar. 1. Perbandingan waktu proses Apriori dan FP Growth

Analisis asosiasi atau association rules mining adalah teknik data mining untuk menemukan aturan asosiasi antara suatu kombinasi item . Interestingness measure yang dapat digunakan dalam data mining adalah :

a. Support, adalah suatu ukuran yang menunjukkan seberapa besar tingkat dominasi suatu item atau itemset dari keseluruhan transaksi.

Nilai support sebuah item diperoleh dengan menggunakan rumus berikut:

$$
\operatorname{Support}(A)=\frac{\text { Jumlah } \text { transaksi mengandung } A}{\text { Total Transaksi }}
$$

Nilai support dari 2 item diperoleh dengan menggunakan rumus :

$$
\begin{aligned}
& \text { Support }(A, B) \\
& =\frac{\sum \text { Transaksi mengandung Adan } B}{\sum \text { Transaksi }}
\end{aligned}
$$

b. Confidence, adalah suatu ukuran yang menunjukkan hubungan antar dua item secara conditional (berdasarkan suatu kondisi tertentu).

Confidence dihitung dengan rumus :

$$
\begin{aligned}
& P(B \mid A) \\
& =\frac{\sum \text { Transaksi mengandung Adan } B}{\sum \text { Transaksi Mengandung } A}
\end{aligned}
$$

\section{Algoritma Apriori}

Pada paper [1] penulis memperkenalkan algoritma yang diberi nama Apriori. Langkah pertama dari algoritma Apriori menghitung kemunculan item untuk menentukan suatu itemsets besar. Langkah berikutnya adalah mencari $k$, yang terdiri dari dua fase. Pertama, itemsets besar $L k-i$ ditemukan di jalur $(k-1)$ digunakan untuk menghasilkan kandidat itemsets $c k$, menggunakan fungsi apriorigen. Selanjutnya, database dipindai dan dukungan kandidat di $c k$ dihitung. Agar lebih cepat perlu langkah efisien untuk menentukan kandidat di $c k$ yang terdapat di transaksi yang diberikan $t$.

Bentuk algoritma Apriori dapat dituliskan seperti nampak di Gambar. 2.

$$
\begin{aligned}
& L 1=\{\text { frequent itemset with one element }\} \\
& \text { for }\left(k=2 ; L_{k-1} \neq \varnothing, k++\right) \\
& \{ \\
& C_{k}=\text { apriori-gen }\left(L_{k-1}\right) ; \quad \text { //pembuatan } \\
& \text { kandidat }
\end{aligned}
$$$$
\text { //baru }
$$

$$
\begin{aligned}
& \text { for all transactions } t \\
& \{ \\
& C_{t}^{\prime}=\operatorname{subset}\left(C_{b} t\right) ; \quad / / k a n d i d a t y a n g \\
& \text { //tampil pada } t \\
& \text { for all candidates } c \in C_{t}^{\prime} \text { do } \\
& \text { c.count }++ \text {; } \\
& \text { \} } \\
& L_{k}=\left\{c \in C_{t}^{\prime} \mid \text { c.count } \geq \text { minsup }\right\}
\end{aligned}
$$$$
\text { \} }
$$

Gambar. 2. Algoritma Apriori

dimana :

$\mathrm{L}:$ himpunan frequent itemset

minsup : minimum support

$\mathrm{C}:$ himpunan kandidat itemset

$\mathrm{c}:$ kandidat itemset

$\mathrm{t}$ : transaksi

\section{Algoritma FP Growth}

Pada paper [4] penulis melakukan perbandingan kinerja algoritma Apriori dengan FP Growth. Algoritma FP Growth membantu menyelesaikan 2 masalah utama pada algoritma apriori, yaitu : menghasilkan sejumlah besar kumpulan kandidat dan berulang kali memindai database. FP Growth diusulkan untuk untuk memberi solusi atas permalahan di algoritma Apriori dengan menggunakan pendekatan yang berbeda dari paradigma yang digunakan pada algoritma Apriori, yaitu : strategi divide-and-conquer. Kelebihan dari algoritma FP Growth adalah hanya melakukan 2 kali pemindaian ke database dan tidak membentuk kumpulan kandidat yang besar.

Pertama kali algoritma FP Growth membentuk freuent 
pattern tree atau disebut juga FP-Tree. Proses penyusunan FP-Tree dari mulai representasi awal transaksi untuk menentukan frequent itemset, setelah didapatkan frequent itemset kemudian dilanjutkan ke perhitungan association rule, menghitung rule yang dihasilkan dari penerapan metode FP Growth untuk mendapatkan pola terbaik dari pola-pola yang ada. Hasil akhir pola dari perhitungan association rule merupakan hasil rekomendasi sebagai bahan acuan terbaik dalam menentukan item atau produk yang paling sering dibeli oleh konsumen.

Algoritma FP Growth ditunjukkan oleh Gambar. 3.

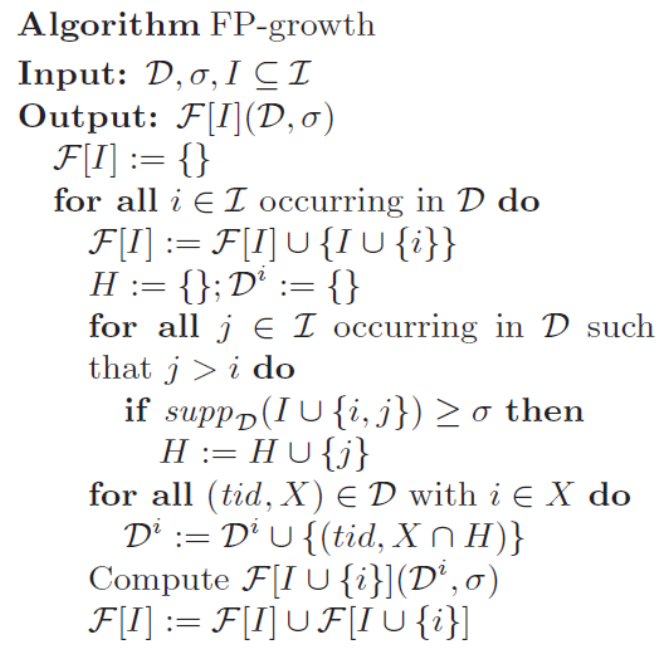

Gambar. 3. Algoritma FP Growth

Metodologi algoritma FP-Growth bisa diperinci sebagai berikut :

1. Menentukan nilai minimum support, misalnya ditentukan 40\%. Deangan asumsi jumlah transaksi 9 maka nilai minimum support count adalah $40 / 100 * 9=3,6$ (dibulatkan ke atas jadi 4).

2. Berikutnya adalah menghitung jumlah kemunculan masing-masing item (support count).

3. Selanjutnya cari item yang memenuhi minimum support count, urutkan support count secara descending (besar ke kecil) dan itemset secara ascending (kecil ke besar).

4. Daftar itemset dan support count itu bisa disebut juga sebagai header table, selanjutnya dibuat database transaksi baru yang mana dilakukan pengurutan list of item sesuai urutan support count sekaligus membuang item yang tidak ada di dalam header table tersebut.

5. Dengan mengunakan database transaksi baru dilakukan pembuatan FP-Tree, dimulai dari transaksi ke-1, 2, dan seterusnya.

6. Dengan menggunakan FP-Tree yang telah dibangun di tahap sebelumnya, dilakukan pembangkitan conditional pattern base.

7. Hitung support count dari setiap item pada setiap conditional pattern base, untuk masing-massing item yang memiliki jumlah support count lebih besar atau sama dengan minimum support count akan dibangkitkan menjadi conditional FP-Tree.

8. Berikutnya adalah pencarian Frequent Itemset, apabila conditional FP-Tree merupakan lintasan tunggal (single path), maka didapatkan frequent itemset dengan melakukan kombinasi item untuk setiap conditional FP-Tree. Jika bukan lintasan tunggal, maka dilakukan pembangkitan FP-Growth secara rekursif (proses memanggil dirinya sendiri).

9. Tahap selanjutnya adalah pencarian strong association rule. Strong association rule adalah rule yang memenuhi syarat minimum support dan minimum confidence. Tahap pencarian strong association rule dilakukan dengan langkah :

a. Untuk setiap frequent itemset $l$ dari , dibangkitkan semua non-empty subset dari $l$.

b. Untuk setiap non-empty subset $s$ dari $l$, menghasilkan rule :

$$
\begin{aligned}
& \mathrm{s} \Rightarrow(\mathrm{l}-\mathrm{s}) " j i k a \frac{\text { support_count }(l)}{\text { support_count }(s)} \\
& \geq \min \_c o n f
\end{aligned}
$$

dimana min_conf adalah minimum confidence.

Untuk analisis digunakan dataset french retail dan bakery shop. Minimum support ditentukan sebesar $1 \%$ dan minimum confidence adalah 50\%. Komputer yang digunakan untuk ujicoba memiliki spesifikasi : processor Inter ${ }^{\circledR}$ Core $^{\mathrm{TM}}$ i5-4210U, memori utama 4GB, dan operating system Microsoft Windows 10.

Kesimpulan dari penelitian pada paper tersebut menyatakan bahwa FP Growth memerlukan waktu lebih cepat pada segala pengujian, baik saat produk dikurangi maupun tidak.

\section{E. Hybrid-Dimension Association Rules}

Pada paper [5] penulis menerapkan konsep multidimensional yang mana digunakan 2 faktor atau variable untuk keputusan ini, yaitu : barang yang dibeli bersamaan dan waktu transaksi. Terdapat beberapa langkah untuk melakukan data mining, dimulai dari pre-prosesing, menentukan frequent itemsets, menentukan association rules.

Percobaan dilakukan menggunakan data transaksi dari minimarket $\mathrm{X}$ yang ingin melakukan analisis kebiasaan berbelanja pelanggan.

Hasil dari percobaan menunjukkan suatu rules bahwa pelanggan berbelanja di hari Minggu untuk membeli Aqua Isi Ulang dan Club Isi Ulang, yang mana hal ini memenuhi kriteria Hybrid-Dimension Association Rules.

\section{F. Perbedaan Algoritma Apriori dan FP-Growth}

Secara umum bisa digambarkan bahwa ada beberapa hal yang membedakan antara algoritma Apriori dan algoritma FP-Growth, berikut ini adalah ringkasannya :

Kekurangan algoritma Apriori :

- Membutuhkan ruang penyimpan besar

- Membutuhkan waktu proses lebih lama

- Menggunakan memori lebih banyak

- Kurang akurat

- Melakukan pembacaan ke database berulangkali 
Sebaliknya pada algoritma FP-Growth terdapat banyak kelebihan, diantaranya adalah :

- Membutuhkan ruang penyimpan kecil

- Membutuhkan waktu proses lebih singkat

- Menggunakan memori lebih sedikit

- Lebih akurat

- Hanya 2 kali melakukan pembacaan ke database

\section{METODOLOGI PENELITIAN}

Penelitian dilakukan dengan mengikuti ketentuan seperti di bawah ini.

\section{A. Dataset}

Dataset yang digunakan untuk pengujian adalah transaksi penjualan real di Swalayan KSU Sumber Makmur dari tahun 2015 sampai dengan 2019. Data transaksi akan dikelompokkan untuk masing-masing tahun untuk diolah dengan 2 aplikasi data mining, yaitu Weka dan Orange. Selain dilakukan pengolahan data masing-masing tahun juga akan dilakukan pengolahan untuk semua transaksi dari tahun 2015-2019.

Untuk pengolahan data dengan aplikasi Weka terdapat banyak format file yang bisa diterima, contohnya : arff, arff.gz, bsi, csv, dat, data, json, json.gz, libsvm, m, names, xrff, xrff.gz. Untuk penelitian ini digunakan file dengan format "Attribute-Relation File Format" (.ARFF) yang merupakan file ASCII teks. Ada 3 bagian penting di file .arff yaitu : @relation, @attribute, dan@data. Berikut ini adalah isi file .ARFF dengan nama relasi "transaksi" yang mengandung 14 attribut dan 9 transaksi :

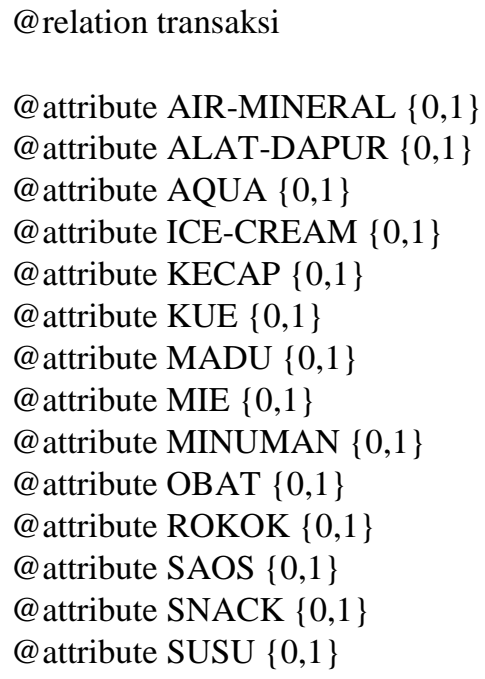

Untuk pengolahan data dengan aplikasi Orange juga terdapat beberapa format file yang bisa diterima, yaitu : tabdelimited, csv, basket. Untuk penelitian ini digunakan file dengan format "basket file" (.BASKET) yang merupakan file ASCII teks dengan pemisah tanda koma (,) antara masingmasing item data dalam satu transaksi. Berikut ini adalah isi file .BASKET yang mengandung 15 transaksi :

\author{
ICE CREAM \\ AIR MINERAL,AQUA,KUE,SNACK,SUSU \\ ALAT DAPUR,MIE \\ MINUMAN,ROKOK,SUSU \\ OBAT \\ ALAT DAPUR \\ KECAP,SAOS \\ SAOS \\ MADU \\ PAMPERS,SUSU \\ ALAT DAPUR,MINUMAN SERBUK \\ ROKOK \\ MINYAK GORENG,SABUN,SUSU \\ MINUMAN JUS,ROKOK \\ MINUMAN,OBAT,PERMEN,SNACK,SUSU,TEH,TISU, \\ WAFER
}

\section{B. Aplikasi Pengolah Dataset}

Aplikasi yang digunakan untuk mengolah dataset adalah Weka versi 3.8.4. Aplikasi Weka digunakan dalam penelitian untuk mengolah data yang diteliti. Weka juga digunakan untuk menampilkan association rules yang dapat disimpulkan dari hasil penerapan associator FP Growth terhadap sejumlah atribut penjualan di Swalayan KSU Sumber Makmur.

Selain dengan aplikasi Weka digunakan juga aplikasi Orange versi 3.24.1 untuk melihat adanya perbedaan hasil association rules yang didapatkan. Pada aplikasi Orange versi 3 untuk bisa menjalankan fungsi association perlu ditambahkan adds-on terlebih dahulu dengan nama Orange3Associate yang mana pada saat penelitian ini dilakukan masih menggunakan versi 1.1.6.

\section{HASIL EKSPERIMEN DAN PENELITIAN}

Penelitian dilakukan dengan data transaksi penjualan sesungguhnya yang ada di Swalayan KSU Sumber Makmur dari tahun 2015 sampai dengan 2019. Pengolahan data yang diteliti dilakukan dengan aplikasi Weka dan didapatkan rules mengikuti konfigurasi yang dimasukkan di jenis associator yang dipilih, dalam penelitian ini digunakan FP Growth. Nilai minimum support dimasukkan di isian lowerBoundMinSupport dengan range 0 sampai dengan 1 untuk mewakili $0 \%$ sampai dengan $100 \%$. Nilai minimum confidence dimasukkan di bagian minMetric di bawah pilihan metricType yang sudah terpilih secara otomatis di confidence. Nilai minimum confidende juga berada pada range dengan range $0 \%$ sampai dengan 1 untuk mewakili 0 sampai dengan $100 \%$. Salah satu contoh hasil dari associator output yang berupa daftar rules yang memenuhi kriteria ditampilkan seperti pada Gambar. 5. 


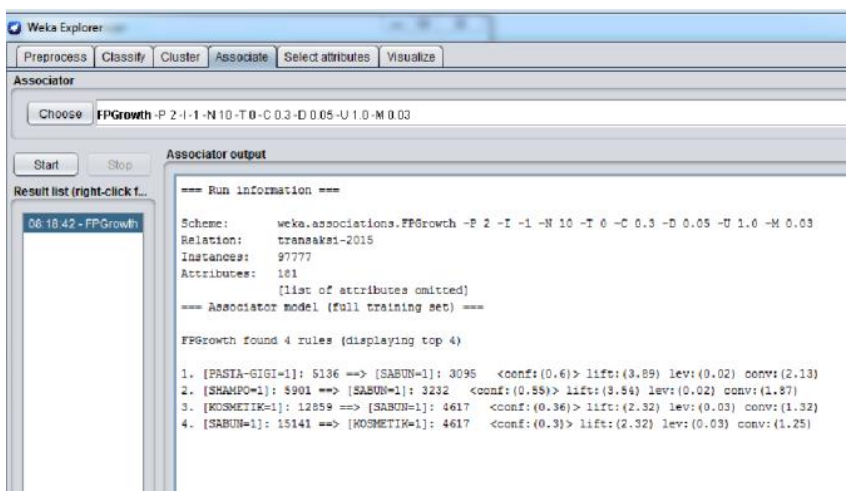

Gambar. 5. Contoh Associator output aplikasi Weka

Pada aplikasi orange bisa dipilih nilai minimum support dan minimum confidence yang diinginkan di bagian slider minimal support dan minimal confidence. Dari pengolahan data dengan aplikasi Orange didapatkan tampilan seperti pada Gambar. 6.

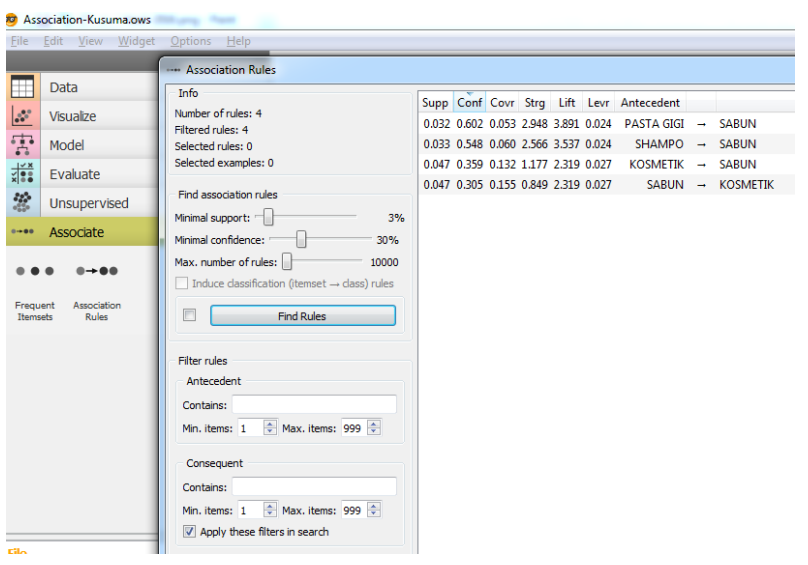

Gambar. 6. Contoh tampilan Association rules aplikasi Orange

Agar mendapatkan nilai minimum support yang tepat maka dilakukan percobaan dengan nilai tertentu misalnya $30 \%$. Dengan nilai minumum support $30 \%$ ternyata belum menghasilkan rules karena variasi barang yang diolah cukup banyak yakni mencapai 218 jenis barang untuk seluruh data antara tahun 2015-2019 dan jumlah instance/transaksi adalah 612.349. Dengan dataset semacam itu maka nilai minimum support yang bisa menghasilkan rules dan tidak terlalu banyak rules yang dihasilkan adalah 0.03 atau $3 \%$.

Nilai minimum confidence juga dilakukan percobaan dengan menggunakan nilai yang cukup rendah dulu, misalnya : $50 \%$ atau 0.5 di aplikasi Weka. Dengan kombinasi nilai minimum support $30 \%$ dan nilai minimum confidence $50 \%$ ternyata hanya didapatkan 2 rules sehingga dicoba lagi dengan menurunkan nilai minimum confidence ke 20\%, hasilnya didapatkan 12 rules. Karena rules yang muncul sudah terlalu banyak dan yang terendah bernilai confidence 0.21 atau $21 \%$ maka ditentukan menggunakan nilai confidence $30 \%$ yang menghasilkan 4 rules.

Hasil uji coba berbagai macam nilai minimum support dan confidence dengan menggunakan data tahun 2015-2019 yang memiliki 218 attributs dan 612.439 instances ditunjukkan oleh Tabel 1 .

TABEL 1

HASIL UJI COBA BERBAGAI MACAM NILAI MINIMUM SUPPORT DAN CONFIDENCE

\begin{tabular}{cccc}
\hline \hline $\begin{array}{c}\text { Minimum } \\
\text { Support }(\%)\end{array}$ & $\begin{array}{c}\text { MiNIMUM } \\
\text { CONFIDENCE } \\
(\%)\end{array}$ & $\begin{array}{c}\text { JUMLAH } \\
\text { ASSOCIATI } \\
\text { ON RULE }\end{array}$ & $\begin{array}{c}\text { NILAI } \\
\text { CONFIDENCE } \\
\text { CE TERTINGGI }\end{array}$ \\
\hline 10 & 90 & 0 & 0 \\
5 & 90 & 0 & 0 \\
1 & 80 & 0 & 0 \\
1 & 70 & 2 & 80 \\
1 & 60 & 7 & 80 \\
1 & 50 & 8 & 80 \\
1 & 40 & 20 & 80 \\
1 & 30 & 43 & 80 \\
1 & 20 & 102 & 80 \\
1 & 10 & 166 & 80 \\
2 & 10 & 42 & 62 \\
3 & 10 & 12 & 63 \\
4 & 10 & 4 & 62 \\
5 & 10 & 2 & 37 \\
6 & 10 & 0 & 0 \\
5 & 20 & 2 & 37 \\
4 & 30 & 3 & 62 \\
3 & 30 & 4 & 63
\end{tabular}

Perbandingan hasil association rule dari kedua aplikasi tersebut nampak seperti pada Tabel 2. Dari Tabel 2. bisa diketahui jika rule terbaik atau menarik adalah :

$$
\begin{aligned}
\text { beli PASTA GIGI } & \Rightarrow \text { beli SABUN [support } \\
& =3,7 \%, \text { confidence }=63 \%]
\end{aligned}
$$

Itu berarti pelanggan yang membeli pasta gigi dan sabun secara bersamaan terjadi pada $3,7 \%$ dari keseluruhan transaksi dan tingkat keyakinan untuk dibeli bersama-sama sebesar 63\%. Kenapa dikatakan menarik karena nilai support dan confidence cukup tinggi.

\section{KesimpUlan}

Nilai minimum support yang tepat pada penelitian dengan menggunakan data transaksi penjualan di Swalayan KSU Sumber Makmur adalah 0.03 atau 3\%. Sedangkan nilai minimum confidence di angka 0.3 atau $30 \%$.

Dari hasil pengolahan data didapatkan 2 strong association dengan nilai confidence paling tinggi, yaitu: jika membeli pasta gigi maka ada kemungkinan sebesar $63 \%$ akan membeli sabun dan jika membeli shampo maka ada kemungkinan $62 \%$ akan membeli sabun.

Pencarian strong association menggunakan aplikasi Weka versi 3.8.4 dan Orange versi 3.24.1 menghasilkan output yang sama meskipun ada perbedaan cara menampilkan nilai confidence yang mana Orange dengan 1 desimal sedangkan Weka tanpa desimal. 
TABEL 2

PERBANDINGAN ASSOCIATION RULES HASIL DARI WEKA DAN ORANGE

\begin{tabular}{|c|c|c|c|c|c|}
\hline & & & \multicolumn{2}{|c|}{ WEKA } & \multirow{2}{*}{$\begin{array}{c}\text { ORA } \\
\text { NGE } \\
\text { CON } \\
\text { FID } \\
\text { ENC } \\
\text { E }\end{array}$} \\
\hline $\begin{array}{c}\text { TAH } \\
\text { UN }\end{array}$ & $\begin{array}{c}\text { ANTECEDE } \\
\text { NT }\end{array}$ & $\begin{array}{c}\text { CONSEQUE } \\
\text { NT }\end{array}$ & $\begin{array}{c}\text { SUP } \\
\text { POR } \\
\text { T }\end{array}$ & $\begin{array}{c}\text { CONFI } \\
\text { DENC } \\
\text { E }\end{array}$ & \\
\hline 2015 & $\begin{array}{l}\text { PASTA GIGI } \\
\text { SHAMPO } \\
\text { KOSMETIK } \\
\text { SABUN }\end{array}$ & $\begin{array}{l}\text { SABUN } \\
\text { SABUN } \\
\text { SABUN } \\
\text { KOSMETIK }\end{array}$ & $\begin{array}{l}3,2 \\
3,3 \\
4,7 \\
4,7\end{array}$ & $\begin{array}{l}60,2 \\
54,8 \\
35,9 \\
30,5\end{array}$ & $\begin{array}{l}60 \\
55 \\
36 \\
30\end{array}$ \\
\hline \multirow[t]{3}{*}{2016} & PASTA GIGI & SABUN & 3,1 & 63,1 & 63 \\
\hline & SHAMPO & SABUN & 3,3 & 55,9 & 56 \\
\hline & KOSMETIK & SABUN & 4,6 & 36,5 & 37 \\
\hline \multirow[t]{4}{*}{2017} & PASTA GIGI & SABUN & 4,0 & 64,0 & 64 \\
\hline & SHAMPO & SABUN & 4,4 & 62,5 & 62 \\
\hline & BABY CARE & SABUN & 3,2 & 40,7 & 41 \\
\hline & KOSMETIK & SABUN & 5,1 & 38,4 & 38 \\
\hline \multirow[t]{4}{*}{2018} & SHAMPO & SABUN & 4,8 & 66,1 & 66 \\
\hline & PASTA GIGI & SABUN & 4,0 & 64,5 & 65 \\
\hline & KOSMETIK & SABUN & 5,3 & 38,5 & 38 \\
\hline & SABUN & KOSMETIK & 5,3 & 30,1 & 30 \\
\hline \multirow[t]{5}{*}{2019} & SHAMPO & SABUN & 4,7 & 64,7 & 65 \\
\hline & PASTA GIGI & SABUN & 3,8 & 62,4 & 62 \\
\hline & KOSMETIK & SABUN & 5,5 & 36,7 & 37 \\
\hline & SABUN & KOSMETIK & 5,5 & 32,3 & 32 \\
\hline & SUSU & SNACK & 4,2 & 30,4 & 30 \\
\hline \multirow{4}{*}{$\begin{array}{l}2015- \\
2019\end{array}$} & PASTA GIGI & SABUN & 3,7 & 63,0 & 63 \\
\hline & SHAMPO & SABUN & 4,2 & 61,9 & 62 \\
\hline & KOSMETIK & SABUN & 5,1 & 37,3 & 37 \\
\hline & SABUN & KOSMETIK & 5,1 & 30,2 & 30 \\
\hline
\end{tabular}

\section{DAFTAR PUSTAKA}

[1] R. Agrawal, R. Srikant, and others, "Fast algorithms for mining association rules," in Proc. 20th int. conf. very large data bases, $V L D B, 1994$, vol. 1215, pp. 487-499.

[2] W. Zhang, H. Liao, and N. Zhao, "Research on the FP growth algorithm about association rule mining," in 2008 International Seminar on Business and Information Management, 2008, vol. 1, pp. $315-318$.

[3] A. Trnka, "Market basket analysis with data mining methods," in 2010 International Conference on Networking and Information Technology, 2010, pp. 446-450.

[4] M. Hossain, A. H. M. S. Sattar, and M. K. Paul, "Market Basket Analysis Using Apriori and FP Growth Algorithm," in 2019 22nd International Conference on Computer and Information Technology (ICCIT), 2019, pp. 1-6.

[5] D. H. Setiabudi, G. S. Budhi, I. W. J. Purnama, and A. Noertjahyana, "Data mining market basket analysis' using hybrid-dimension association rules, case study in Minimarket X," in 2011 International Conference on Uncertainty Reasoning and Knowledge Engineering, 2011, vol. 1, pp. 196-199.

[6] J. Han, M. Kamber, and J. Pei, "Data mining concepts and techniques third edition," Morgan Kaufmann Ser. Data Manag. Syst., vol. 5, no. 4, pp. 83-124, 2011. 